\title{
Organisational efforts to improve quality while reducing healthcare disparities: the case of breast cancer screening among Arab women in Israel
}

\author{
Rachel Wilf-Miron, ${ }^{1}$ Noya Galai, ${ }^{2,3}$ Amal Gabali, ${ }^{1}$ Irene Lewinhoff, ${ }^{1}$ Orna Shem Tov, ${ }^{1}$ \\ Omri Lernau, ${ }^{1,4}$ Joshua Shemer ${ }^{1,5}$
}

${ }^{1}$ Maccabi Healthcare Services, Tel Aviv, Israel

${ }^{2}$ Department of Statistics, University of Haifa, Haifa, Israel

${ }^{3}$ The Department of Epidemiology, Bloomberg School of Public Health, Johns Hopkins University, Baltimore, Maryland, USA

${ }^{4}$ Faculty of Health Sciences, Ben-Gurion University of the Negev, Beer-Sheba, Israel ${ }^{5}$ Sackler School of Medicine, Tel Aviv University, Tel Aviv, Israel

\section{Correspondence to} Dr Rachel Wilf-Miron, Department for Quality Promotion in Health Care, Maccabi Healthcare Services, Tel Aviv, 68125, Israel; rachel m@mac.org.il

Accepted 22 January 2010 Published Online First 17 June 2010

\author{
ABSTRACT \\ Objectives (1) To improve quality and equity by \\ increasing utilisation of mammography screening among \\ Israeli Arab women. (2) To explore effectiveness of \\ designing interventions with a combined top-down and \\ bottom-up approach. \\ Design Retrospective study at two periods of time: \\ 2004-intervention's preliminary stages; \\ 2005-intervention's implementation.
}

Setting Maccabi Healthcare Services (MHS), an Israeli health plan serving 1.7 million members at study period; $7 \%$ of them are Arabs by 139 branches, 13 of which serve Arabs exclusively.

Macro-organisational intervention (top

down) Development of a computerised Mammography Promotion System, phone contacts with nonrespondents and intraorganisational reporting of screening rates.

Intensive intervention (bottom up) A local analysis of barriers to care and implementation of tailored solutions. This intervention was initiated and documented in three Arab branches, with spillover to the entire Arab sector.

Measure definition Biennial breast cancer $(\mathrm{BC})$ screening of eligible women.

Improvement measures Changes in $\mathrm{BC}$ screening rates in Arabs and comparisons with overall MHS BC screening rates for 2004 and 2005.

Results In 2005, average BC screening rates in Arab branches increased from $26.7 \%$ to $46.2 \%$ (73\% improvement), while overall MHS screening rates increased from $49.0 \%$ to $63.1 \%$ (29\% improvement). Analysis of the relative differences between 2004 and $2005 \mathrm{BC}$ screening rates indicated statistically significant differences $(p<0.006)$ in rates between the Arab and other branches. These results did not change after adjustment for branch size, region and branch average age.

Conclusions Combined top-down interventions and bottom-up initiatives are effective for formulating programmes to reduce inequality.

\section{SETTING}

Breast cancer (BC) is the leading cause of cancerrelated deaths among Arab and Jewish women in Israel. ${ }^{1}$ Israel's Arab population, currently numbering 1.3 million ( $20 \%$ of total population), resides primarily in rural villages and small towns. The Arab population is characterised by large disparities in education, income, employment as well as health status when compared with the Jewish population. ${ }^{1-4}$ These social factors, in addition to other cultural and behavioural factors, are well documented as influencing health and healthcare utilisation among Israeli minorities, including Arabs. ${ }^{5-7}$ Maccabi Health Care Services (MHS), under the National Health Insurance Law (NHIL) and Israel's universal healthcare system, insures $7 \%$ of the Arab population; the rest are insured by Israel's three other health plans.

MHS was providing services for 1.7 million members in the period covered by the study. Services were and continue to be delivered by selfemployed physicians and other health professionals affiliated with the plan's 139 local branches, distributed among six regions; 13 of these branches are located in Arab towns and villages, and thus serve primarily Arab population. In 2004, MHS instituted a system of performance measurement throughout the organisation to promote quality improvement; results have been published internally and externally to promote transparency. ${ }^{8}$

In 2003-2004, the national biennial breast cancer screening rate (BC screening rate) among Arab women aged $50-74$ was $32 \%$, compared with $54 \%$ among Jewish women in the same age group. ${ }^{9}$ These trends were similar to those observed in the US (age $40+$ ) and the UK (age 50-74), where women belonging to ethnic minorities or to low- to mediumincome groups exhibit lower $\mathrm{BC}$ screening rates and thus more advanced disease at diagnosis. ${ }^{10} 11$

Increased BC screening has been a national objective in Israel since 1997, with personal invitations to undergo mammography screening sent biennially to all women aged 50-74; this service is supplied free of charge. ${ }^{12}$ Yet, by 2004 , the BC screening rate among the national target population stood at $52.0 \%$, with significant gaps between the rates of women from low socio-economic backgrounds and other women (45.8\% and $54.8 \%$, respectively). ${ }^{13}$ Among female members of MHS, the global screening rate was $49.0 \%$. This figure was slightly lower than the national average yet much below the $73.4 \%$ reported by US commercial health plans for women aged 52-69 in the same year. ${ }^{13} 14$ The $\mathrm{BC}$ screening rate for MHS branches serving the Arab population was particularly low when compared with the health plan's regional and total screening rates for 2004 This screening rate became our call for action.

In tandem with macro-level (top-down) organisational efforts, local branch staff initiated focused (bottom-up) attempts to improve screening rates, based on their field experience. The intervention recounted here pertains to these intensive efforts, 
which began in three branches in 2004 and continued throughout 2005. The efforts and results were well documented, with spillover to other Arab branches accompanied by little or no documentation.

\section{OBJECTIVES}

1. To improve quality of care and equity by increasing utilisation of mammography screening among Israeli Arab women aged 52-74, a group insured by MHS and considered to be low users of $\mathrm{BC}$ screening.

2. To explore the effectiveness of designing top-down and bottom-up interventions, which combine macro-organisational with more focused local programmes.

\section{DESIGN}

\section{Key improvement measures}

Measures were devised to reflect the two quality-improvement goals: changes in absolute biennial $\mathrm{BC}$ screening rates in the Arab population and changes in those rates, between the two periods of time, in comparison with changes in overall $\mathrm{BC}$ screening rates in MHS:

1. Absolute rates of $\mathrm{BC}$ screening (defined as the proportion of women aged 52-74 who had had at least one mammogram in the last 2 years) were measured per branch in two time periods: September $2004\left(R_{2004}\right)$ and December $2005\left(R_{2005}\right)$ (figure 1). The measure of change was defined as the relative difference $(R D)$ in $B C$ screening rates, calculated as

$\mathrm{RD}=\frac{\mathrm{R}_{2005}-\mathrm{R}_{2004}}{\mathrm{R}_{2004}}$

2. To facilitate direct comparison of the 13 Arab branches with overall MHS rates, we calculated a standardised rate ratio (SRR) for each target branch, defined as $\mathrm{O}_{\mathrm{i}} / \mathrm{E}^{*}$, where $\mathrm{O}_{i}$ is the rate of women in branch $i=1, \ldots, 13$, who had performed $\mathrm{BC}$ screening, and $\mathrm{E}_{\mathrm{i}}{ }^{*}$ is the expected rate for that branch based on the age-specific screening rates among the organisation's entire female population. An age-adjustment factor was introduced into the formula because this type of screening rate changes with a woman's age.

We considered 2004 as the period of the intervention's preliminary stages (planning and fieldwork) and 2005 as the period of the intervention's implementation.

\section{Data collection}

To gather the data, we used the 'Mammography Indicator,' implemented in the organisation's 'Performance Measurement System,' which derives its data from the operational database housed in the organisation's main computer. The 'Mammography Indicator,' was defined as: 'Woman aged 52-74 who received at least one $\mathrm{BC}$ screening during the last 2 years.' $\mathrm{BC}$ screening rates were assessed at two points in time-September 2004 and December 2005.

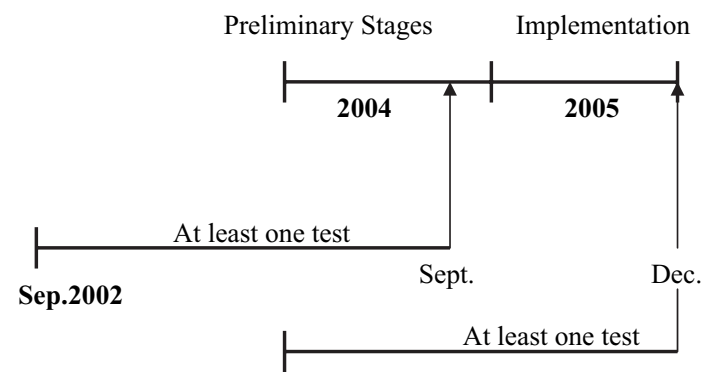

Figure 1 Study time periods.

\section{SELECTION CRITERIA \\ Ethnicity}

At the time of the intervention, the organisation's operational database did not permit precise identification of populations by ethnic affiliation, religion or socio-economic status. Because the 13 branches serve the Arab population exclusively, branch location was chosen as a proxy for ethnic identity. In September 2004, a total of 1429 Arab women were members of the 13 respective branches. Relevant data on all these women were collected and analysed by branch. For purposes of comparison, data on all MHS's 125063 women aged 52-74 were also analysed by age and branch.

The data were extracted from the operational database using the organisation's main computer (IBM-AS400). In three out of the 13 Arab branches-Al-Tira, Tayibe and Kalanswa located in central Israel, together known as the 'Triangle' - a local effort was initiated to intensify the macro-organisational intervention. These special activities are describes bellow.

\section{Data analysis}

Relative differences in $\mathrm{BC}$ screening rates were calculated for each branch $\left(\mathrm{RD}_{\mathrm{i}}, \mathrm{i}=1, \ldots, 139\right)$ using a regression model for log-transformed measurements. Non-parametric methods were also used. The results are presented for the three intensive intervention branches (nos 9, 11, 12), for the other 10 Arab branches (nos 1, 2, $3,4,5,6,7,8,10,13)$ and for all other $126 \mathrm{MHS}$ branches to allow for comparison between the two intervention populations: MHS Arab members and the entire MHS insured population. The SRRs were calculated separately for each year, as overall mammography screening rates changed dramatically between 2004 and 2005 . Confidence Intervals (CIs) were calculated based on Poisson assumptions regarding the rates and Bayer approximation. ${ }^{15}$ SRRs closer to 1 indicate that branch rates did not differ significantly from expected rates based on the health plan's total female population adjusted by age. Similarly, SRRs far from 1 indicate greater differences between the observed and expected screening rates. Since we know retrospectively that there was a spillover of ideas from the 'Triangle' to other Arab branches and that spillover was not documented but reported later upon request, we decided to analyse the 13 branches as one group. All analyses were performed with STATA software (STATA, College Station, Texas).

\section{INTERVENTION}

\section{Macro-organisational intervention (top down)}

As part of macro-level organisational quality-improvement initiatives, a steering committee composed of representatives from the six MHS regions, covering all 139 branches, was mandated to formulate a strategy to improve the $\mathrm{BC}$ screening rate. Efforts were guided by a facilitator who had been trained to apply quality improvement methods and tools. Previous efforts to improve screening were reviewed to identify the most effective features for integration into the current intervention. On the macro-organisational level, the following actions were instituted:

- A Mammography Promotion System was developed using the MHS main computerised system. This system scanned the population monthly to construct a list of members requiring mammography screening and produced invitations, in the form of postcards, to do so.

- Non-respondents to invitations were identified at the branch level and contacted by phone. The steering committee created various 'scripts' to facilitate dialogue. 
- Computerised decision-support tools were developed to notify the primary physician, when entering an eligible patient's electronic file during a medical encounter, as to whether she had undergone screening.

- To encourage peer comparison, physicians also received information comparing their patients' screening rate with regional and organisational rates.

\section{Intensive local intervention (bottom-up)}

In early 2004, A Gabali, a nurse and manager of Maccabi's 'Triangle' branches, constructed a team composed of herself, a physician and the manager of the Kalanswa branch with the aim of identifying the barriers to local implementation of the national programme. The barriers identified were:

- Accessibility-The nearest screening facility was located $30 \mathrm{~km}$ outside the 'Triangle,' with access constrained due to transportation difficulties.

- Social norms-Numerous families disapprove of women leaving the city unaccompanied by a male relative, acting as chaperone. During the screening facility's working hours, few male family members were available to do so.

- Moral values-Due to their religious upbringing, women were often embarrassed by the prospect of a male physician conducting a breast examination. Many women were also fearful of social stigmatisation if it became known that they had undergone screening.

- Lack of Self-Care Values-BC, like other diseases, has traditionally been perceived as a 'natural' life event. Hence, the majority of Arab women in the target age group have not internalised pro-active self-care values.

- Inadequate Information-Arab women, like other ethnic minorities, lacked sufficient information about the disease, the examination, the benefits of early detection and their membership in the national programme's target population. One source of this gap: information is rarely distributed in their mother tongue, Arabic.

- Postcard failure-An unknown proportion of screening invitations did not reach their targets: Because more than one person in Arab extended families bear the same first and last names, delivery errors often occurred.

The 'Triangle' team chose to implement the following solutions:

- Personal contacts were initiated with community leaders to mobilise their support for the programme.

- The team leader (A Gabali) personally went from door to door to convince women to participate in the programme.

- A compact 'treatment package' was constructed for transmission during patient meetings with staff. It included A Gabali's explanation of the examination and its importance, an examination by a physician-always in the presence of a female nurse-and the making of an appointment at the screening facility.

- To remove barriers to care, flexibility was introduced into the clinical protocol as dictated by patient needs. For example, the male physician's examination could be waived if it caused distress.

- Local branch staff organised group transportation to the screening facility for branch members.

Their efforts reached $80 \%$ of the women eligible for $\mathrm{BC}$ Screening. The activities of the 'Triangle' branches were facilitated by members of the MHS BC Screening Steering Committee who were involved in other Arab branch activities and acted as the platform for the spillover of 'Triangle' ideas to other Arab branches. In addition, these actions were supported by the organisation's infrastructure-for example, computerised decision-support tools and centralised production as well as delivery of screening invitations.

\section{RESULTS}

In 2004, MHS membership included 125063 women aged $52-74$, with an overall BC screening rate of $48.98 \%$. The Arab members of the 13 branches included 1429 women in this age group, only $26.73 \%$ of whom had undergone screening in the previous 2 years. The median age of the total population was 59 (mean 60.42), and the IOR was 55-66; the overall SRR for the Arab population in 2004 was $54.59 \%$.

By 2005, the overall female health plan membership in the 52-74 age group had increased slightly, to 133372; of these, $63.07 \%$ had undergone screening in the previous 2 years. Among the 1516 Arab women in the respective age group, $46.17 \%$ had undergone screening. The overall SRR for the Arab population in 2005 was $73.22 \%$.

The age distribution of female MHS members, including Arabs, remained virtually the same in 2005 as in 2004 .

Statistical analyses indicated a significant improvement in BC screening rates in the 13 Arab branches.

Table 1 shows age-specific screening rates for 2004 and 2005 as well as the differences in those rates.

Figure 2 shows the relative difference (RD) between 2004 and 2005 BC screening rates per branch. The figure shows very low rates for many of the Arab branches in September 2004, with a very large change apparent by December 2005. Regression analysis (not shown) on the log-transformed $\mathrm{RD}$ indicated a statistically significant difference $(p<0.006)$ between Arab and other branches. These results did not change after adjustment for branch size, region and average age of the women in each branch.

Figure 3 shows the SRRs at the 95\% CI for the 13 Arab branches in 2004 and 2005. In 2004, most branches exhibited preintervention SRRs well below expected rates, whereas in 2005, some branches displayed SRRs not significantly different from total MHS rates (at an SRR of 1). Branches 9, 11 and 12, the 'Triangle' branches participating in the intensive intervention, demonstrated a significant change. Branches 4 and 8, located in the Bedouin rural settlements of Rahat and Kseife, also presented a significant change, presumably due to the spillover effect.

\section{DISCUSSION}

Initial performance data revealed a significant disparity in quality of care, expressed as differences in BC screening rates.

Table 1 Breast cancer $(\mathrm{BC})$ screening rate (\%) by selected age, total female membership, Maccabi Health Care Services, 2004-2005

\begin{tabular}{lllll}
\hline $\begin{array}{l}\text { Age } \\
\text { deciles }\end{array}$ & $\begin{array}{l}\text { Age } \\
\text { range }\end{array}$ & $\begin{array}{l}\text { BC screening } \\
\mathbf{2 0 0 4}\end{array}$ & $\begin{array}{l}\text { BC screening } \\
\mathbf{2 0 0 5}\end{array}$ & $\begin{array}{l}\text { Difference } \\
\mathbf{2 0 0 4 - 2 0 0 5}\end{array}$ \\
\hline 1 & $52-53$ & 49.65 & 63.65 & 14.00 \\
2 & 54 & 50.82 & 63.33 & 12.51 \\
3 & $55-56$ & 50.25 & 64.10 & 13.85 \\
4 & 57 & 51.63 & 63.64 & 12.01 \\
5 & $58-59$ & 51.16 & 65.24 & 14.09 \\
6 & $60-61$ & 52.93 & 65.54 & 12.61 \\
7 & $62-64$ & 48.96 & 63.81 & 14.85 \\
8 & $65-67$ & 48.48 & 63.39 & 14.91 \\
9 & $68-70$ & 46.42 & 60.98 & 14.56 \\
10 & $71-74$ & 39.98 & 55.61 & 15.63 \\
Total & & 48.98 & 63.07 & 14.09 \\
\hline
\end{tabular}




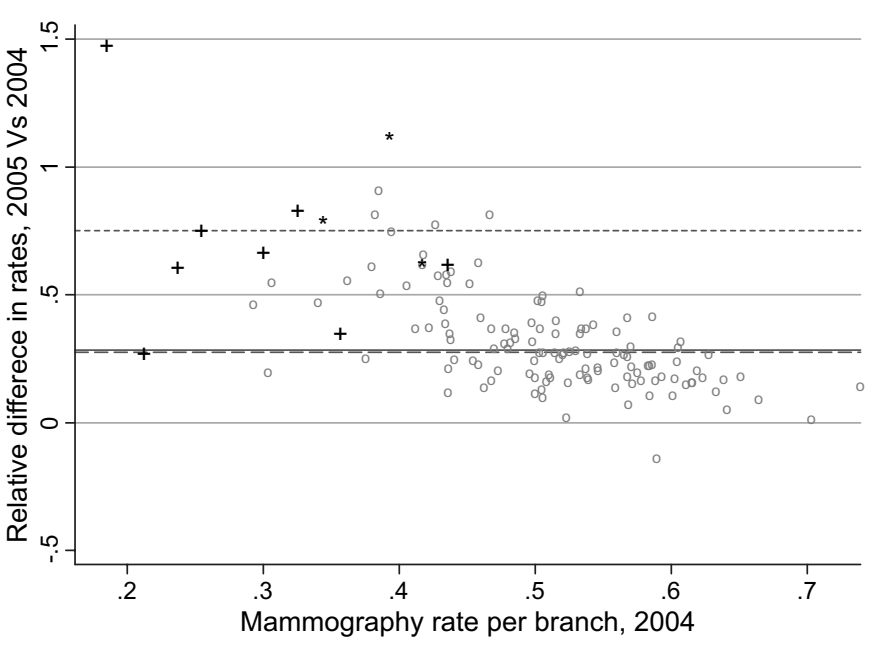

Figure 2 Comparison of relative change in breast cancer screening rate (mammography rate), 2004-2005, by Maccabi Healthcare Services branch without the two branches with relative difference $\geq 2$.

The local team chose to preferentially allocate organisational resources to reduce disparities based on two factors: (1) the organisational effort to promote utilisation of $\mathrm{BC}$ screening among all population groups given MHS overall rates, which were lower than national and international benchmarks; and (2) the team's in-depth familiarity with the special needs and barriers to care characterising the local population, coupled with a readiness to invest additional resources. These two factors formed the foundations of the top-down combined with the bottom-up approaches. The organisation's extensive activities in this field culminated in the creation of a dialogue, a learning process and a solid infrastructure on which local (bottom-up) initiatives could develop.

The uniqueness of this three branches' intervention effort rests primarily in the fact that the barriers were explored by local people, all of whom are Israeli Arab health professionals, well respected and trusted by their staff, the local population and community leaders. Added was the encouragement and facilitation provided by the organisation. The spillover to other Arab branches was enabled by concurrent horizontal activities

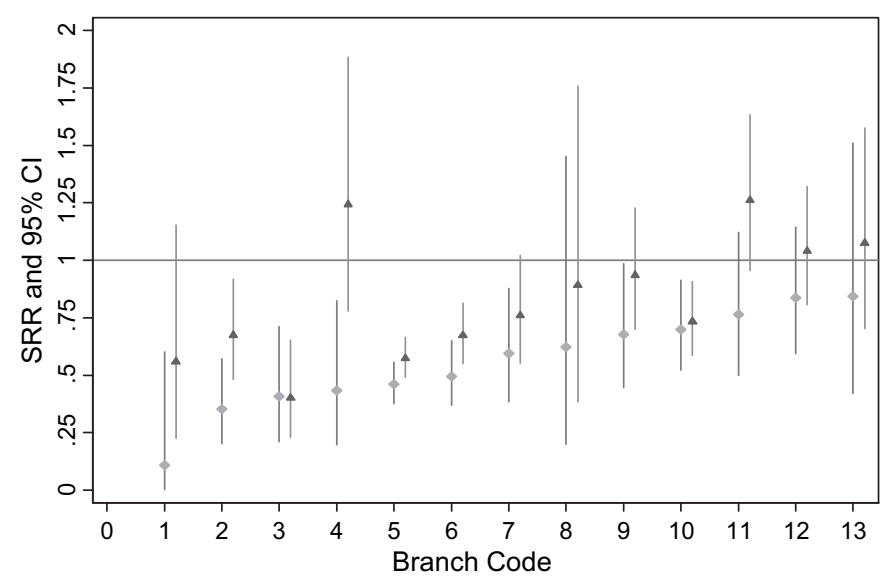

Figure 3 Comparison of breast cancer screening rate among Arab women, members of the 13 target branches and all female members of Maccabi Healthcare Services 2004 (in grey) and 2005 (in black), using standardised rate ratios (SRRs) and 95\% Cl. initiated by the BC Screening Steering Committee, which nurtured a dialogue between and within the organisation's Arab branches.

The process implemented in the 'Triangle' became a 'big story' in the organisational discourse and produced several important organisation-wide benefits. Disparities in healthcare were no longer viewed as trivial and now acknowledged as calls for strategic action; an 'equity discourse,' instituted throughout the organisation, has led to further actions. Among the latter was the introduction of a combined approach to reduce disparities within other clinical domains, an approach that rested on field confirmation of the salience of bottom-up input for the tailoring of quality improvement efforts to priority populations. In addition, dissemination of the transparent performance measure heightened management recognition of and commitment to the screening programme's equitable implementation.

This case has confirmed once more that careful analysis of the place-specific context is essential for understanding differences across communities stemming from various causal factors. ${ }^{16}$ It demonstrates that specific contextual characteristics-education, family income and continuous health insurance-are independently associated with BC screening. Ethnicity, as reflected in socio-economic status, access to healthcare and life style disparities, was likewise found to be associated with BC screening utilisation and stage of $\mathrm{BC}$ at diagnosis. ${ }^{17}$ These variables can therefore be used to identify populations in which women are at increased risk for delayed $\mathrm{BC}$ diagnosis. They can also inform the planning phase of initiatives meant to enhance $\mathrm{BC}$ screening and reduce disparities in treatment outcomes. ${ }^{18}$ We would therefore recommend that organisational efforts to increase equity and reduce disparities in healthcare utilisation and health outcomes consider these variables when planning interventions, especially those targeted at populations at risk.

The local intervention was developed during the experimental learning phase without any notice given to similar activities elsewhere. This may explain what happened in branches 4 and 8, two geographically distant Bedouin settlements. News of the 'Triangle's' experience had been disseminated to other Arab branches where it promoted undocumented local activities, what can be considered a spillover effect. Retrospectively, we learnt that staff in the latter two branches also negotiated with local community leaders, used a mobile screening facility to enhance accessibility and spread invitations door to door.

The 'Triangle' case also invites evaluation of the two major attitudes to performance recognition and reward: (1) an emphasis on absolute performance, which is advantageous to stronger units, and (2) recognition of relative improvements in performance, which provides incentives to weaker units beginning at lower levels of performance and therefore more prone to achieving greater relative change. Because equity is an important dimension of quality, we concluded that there was great value in recognising the Arab branches that had begun with lower screening rates and made greater relative progress in consequence.

\section{LIMITATIONS OF THE RESEARCH}

The study's limitations relate primarily to the employment of proxies - the local plan branch-for identification of the research population. Because the study focused on women from the local branches serving almost exclusively Arab populations, Arab women in ethnically mixed cities such as Nazareth, Acre, Jaffa and Haifa were unrepresented. We assume that in mixed cities, screening rates are higher, and barriers to care somewhat differ. This does not, however, undermine the validity of the results or the approach taken in the selected homogeneous branches. 


\section{LESSONS LEARNT AND INTERPRETATION}

Based on the experience reported, invitations for mammography as well as other screening were recently translated into Arabic and Russian, the two major languages spoken in Israel other than Hebrew. We expect this effort to facilitate contact with plan members and improve transmission of educational materials.

It has also been decided to investigate expansion of the organisation's operational database. We are interested in adding parameters such as ethnic affiliation and socio-economic status, to be correlated with performance indicators so as to broaden opportunities to identify target populations and decrease disparities.

Despite the significant improvement observed, BC screening rates among the Israeli Arab population remained far from optimal by the end of 2005. However, in subsequent years, disparities became a managerial concern, with equity issues accepted as an integral part of the organisational discourse. In 2008, MHS adopted equity in service provision and health outcomes as a major strategic goal. Analysis of performance measures according to socio-demographic profile supported identification of member populations at risk, which led to construction of the first MHS Organisational Equality Report. ${ }^{19}$ A wide range of disparities in clinical and prevention domains, characterising the Arab minority as well as other population segments with a low socio-economic status, were consequently revealed. The age-adjusted $\mathrm{BC}$ screening rate among the Arab population in 2008 was 0.88 of the rate among the Jewish population. As a result, it was decided to allocate preferential resources to populations at risk, and decisions relevant to care provision were taken. These included training of health professionals and administrative staff in the cultural adaptation of health services, an increase in the linguistic accessibility of educational materials and so forth.

As this initiative has shown, quality-improvement measures can reflect as well as respond to equity considerations. Whitehead has proposed an 'action spectrum on inequalities in health,' beginning with measurement, continuing through recognition, awareness-increasing, willingness to take action, local initiatives, more-structured development and comprehensive coordinated policy. ${ }^{20}$ This approach is being more stringently adopted throughout the organisation.

The reported intervention increased organisational receptiveness to the synergy emerging from adjustment of top-down policy to bottom-up implementation requirements, based on recognition of the legitimacy-and necessity-of each approach for quality healthcare delivery. This outcome is being incorporated into the plan's organisational culture as a cornerstone of equity-oriented strategic planning and implementation. We anticipate that these measures will alter the prognosis that 'geography is destiny.'

\section{What did not work?}

We now know that a few elements in the top-down intervention did not work. For instance, the feedback that physicians regularly received regarding $\mathrm{BC}$ screening performance was ineffective, mainly because a structured, non-judgemental dialogue between managers and physicians following these reports did not take place throughout the organisation.

Finally, we assume that our experience and study results can be beneficial for other Israeli and non-Israeli health services interested in closing health disparities in BC screening utilisation as in other clinical domains where low use among ethnic and cultural minorities is a reality. As this case has taught, we assume that each organisation should tailor interventions to its own population.

\section{What is already known on this issue}

- Ethnic minorities and low socio-economic status groups underutilise health services and display poor health outcomes.

- Careful analysis of the place-specific context is essential for understanding differences across communities stemming from various causal factors.

- Avoidance of a 'one size fits all' policy can improve equity by setting the stage for heterogeneity in intervention planning and implementation, necessary for programme adjustment to community characteristics and health needs.

\section{What this study adds}

- Field staff can contribute significantly to reducing healthcare disparities due to their familiarity with local barriers to quality care and input when constructing tailor-made solutions.

- The power of local stories lies in its potential to increase organisational awareness of healthcare disparities and stimulate corrective action.

- Intuitive responses to messages from the field and 'outside the box' thinking can lead to innovative solutions. This approach should be considered an addition to the quality 'toolbox.'

Acknowledgements We would like to thank J Hatib, branch medical director, and A Marae, branch manager, Kalanswa, for their determination and dedication in supporting the project and in bringing this story to the organisation's attention.

\section{Competing interests None.}

Contributors Contributors/guarantors of the paper: RW-M and NG.

Provenance and peer review Not commissioned; externally peer reviewed.

\section{REFERENCES}

1. The Israel Center for Disease Control. The health status of the Arab population in Israel 2004. Jerusalem: A Ministry of Health Publication, 2005

2. The Israeli Central Bureau of Statistics. The Arab population in Israel No. 26, 2002 (International version-statistilite 50, 2003)

3. Adva Center, The Israeli Employment Services. Table: Percent of unemployment by residence. Department of Research and Information, Ministry of Industry, Trade and Labour, 2004

4. The Israeli Central Bureau of Statistics. Statistical Abstract of Israel. Publication No. 55, Jerusalem, 2004.

5. Baron-Epel 0, Kaplan G. Can subjective and objective socioeconomic status explain minority health disparities in Israel? Soc Sci Med 2009;69:1460-7.

6. Baron-Epel 0. Attitudes and beliefs associated with mammography in a multiethnic population in Israel. Health Educ Behav. Published Online First: 2009 Aug 18.

7. Baron-Epel 0, Friedman N, Lernau O. Fatalism and Mammography in a Multicultural Population. Oncol Nurs Forum 2009;36:353-61.

8. Friedman N, Kokia E, Shemer J. Health Value Added: linking strategy, performance, and measurement in healthcare organizations. Israel Medical Association Journal (IMAJ) 2003;5:3-8

9. The Israel Central Bureau of Statistics. National Health Survey in Israel, stage A. women's health. A Project of the World Health Organization, Regional Office for Europe, Publication 237, 2004.

10. Agency for Healthcare Research and Quality. National Healthcare Disparities Report. AHRO publication No. 06-0017, 2005.

11. Adams J, White M, Forman D. Are there socioeconomic gradients in stage and grade of breast cancer at diagnosis? Cross sectional analysis of UK cancer registry data. BMJ 2004;329:142-3.

12. The Israel Cancer Association. http://www.cancer.org.il.

13. Porath A, Rabinowitz G, Raskin Segal A. Quality indicators for community health care in Israel. 2002-2004. Public report. Ben Gurion University of the Negev, Ministry of Health, 2005.

14. National Committee for Quality Assurance. The state of health care quality. Washington, DC, US, 2005. http://www.ncqa.org. 
15. Breslow NE, Day NE. Statistical methods in cancer research. The design and analysis of cohort studies. Vol II. Lyon, France: International Agency for Research on Cancer, 1987.

16. Mobley LR, Kuo TM, Driscoll D, et al. Heterogeneity in mammography use across the nation: separating evidence of disparities from the disproportionate effects of geography. Int J Health Geogr 2008;7:32.

17. Li CI. Racial and ethnic disparities in breast cancer stage, treatment, and survival in the United States. Ethn Dis 2005;15(2 Suppl 2):S5-9.
18. Litaker D, Tomolo A. Association of contextual factors and breast cancer screening finding new targets to promote early detection. J Women's Health (Larchmt) 2007:16:36-45.

19. Wilf-Miron R, Yaari E, Lewinhoff I, et al. Health equality report: disparities in health measures and directions for action. Internal Report. Tel Aviv, Israel: Maccabi Health Care Services, 2009.

20. Whitehead M. Diffusion of ideas on social inequalities in health: A European perspective. Milbank Ouarter 1998;76:469-90. 